УДК 632.95:633.854.78

СКРИНИНГ ГЕРБИЦИДНЫХ АНТИДОТОВ ДЛЯ РАСТЕНИЙ ПОДСОЛНЕЧНИКА В РЯДУ ПРОИЗВОДНЫХ ТРИАЗОЛОПИРИМИДИНОВ

\author{
1 Дмитриева И.Г., ${ }^{2}$ Дядюченко Л.В.
}

${ }^{\prime}$ ФГБОУ ВО «Кубанский государственный аграрный университет имени И.Т. Трубилина», Kраснодар, e-mail: irina.bona.mente@gmail.com;

${ }^{2}$ ФББНУ «Всероссийский научно-исследовательский институт биологической защиты растений», Kраснодар, e-mail: ludm.dyadiuchenko@yandex.ru

При выращивании сельскохозяйственных культур широко используются химические средства борьбы с сорной растительностью. Однако гербициды наносят вред не только сорнякам, но и культурным растениям. В практике возможны случаи непреднамеренного повреждения значительных площадей сельскохозяйственных культур гербицидными препаратами. Подсолнечник - основная масличная культура в нашей стране, он занимает три четверти площади посевов всех масличных культур, а Краснодарский край является безусловным лидером по производству семян подсолнечника. В то же время подсолнечник является очень чувствительной культурой к гербицидам группы 2,4-Д, и при неумышленном воздействии последних потери урожая могут быть невосполнимыми. Одним из приёмов как повышения урожайности подсолнечника и выхода масла, так и спасения урожая в случае такой необходимости является создание и использование антидотов, нивелирующих негативное действие гербицидов на растения и окружающую среду. Наша работа посвящена поиску антидотов для вегетирующих растений подсолнечника от повреждающего действия фитотоксикантов группы 2,4-Д в ряду производных триазолопиримидинов. С этой целью нами синтезирована серия $\mathrm{N}$-замещённых 4,6-диметил-1,2,4-триазоло[1,5-b]пиримидил-3-сульфониламидов. В условиях лабораторного опыта отобраны соединения, проявляющие антидотный эффект как на стеблях, так и на корнях проростков подсолнечника на уровне 20-61\%. В полевом опыте вегетирующие растения подсолнечника, на фоне 40-50\%-ного поражения гербицидом, через 1 или 3 суток проводили обработку антидотом в дозе 40 г/га. Выявлены 2 вещества, проявившие существенную антидотную активность. Под их влиянием прибавка урожая подсолнечника составила 5,3-5,5 и 6,4-6,6 ц/га соответственно, что соответствует 35-39 и 44-46\%-ному антидотному эффекту. Таким образом, найденные соединения могут быть использованы в качестве действующих веществ для создания гербицидных антидотов.

Ключевые слова: гербициды, потери урожая, подсолнечник, антидоты, скрининг, триазолопиримидины, антидотный эффект

\title{
SCREENING HERBICIDE ANTIDOTES FOR SUNFLOWER PLANTS IN THE LINE OF TRIAZOLOPYRIMIDINE PRODUCTS
}

\section{${ }^{1}$ Dmitrieva I.G., ${ }^{2}$ Dyadyuchenko L.V.}

${ }^{1}$ I.T. Trubilin Kuban State Agrarian University, Krasnodar, e-mail: irina.bona.mente@gmail.com; ${ }^{2}$ All-Russian Research Institute of Biological Plant Protection, Krasnodar,

e-mail: ludm.dyadiuchenko@yandex.ru

In production of agricultural crops, chemicals are widely used to control weed vegetation. Herbicides can harm not only the weeds, but also damage crop plants. Actually, there are some examples of unintentional damage to large areas of crops by herbicides. Sunflower is the main oil-plant in our country, it occupies three quarters of all oil-plant areas, and Krasnodar region is an absolute leader in production of sunflower seeds. At the same time, sunflower is very sensitive to herbicides of group 2,4-D, and when unintentionally being effected by the latter yield, losses may be irretrievable. One of the ways to increase yields of sunflower and the output of oil, as well as save the crop, if necessary, is development and implementation of antidotes that neutralize negative effects of herbicides upon plants and the environment. Our study is aimed to search for 2.4-D antidotes for sunflower growing plants against the damaging effect of phytotoxicants of group 2,4-D in the line of triazolopyrimidine priducts. Thus, we synthesized a series of $\mathrm{N}$-substituted 4,6-dimethyl-1,2,4-triazolo [1,5-b] pyrimidyl-3-sulfonylamides. Under the conditions of laboratory experiment, compounds that exhibitied an antidotal effect both on the stems and on the roots of sunflower seedlings at a level of $20-61 \%$ were selected. Under the conditions of the field experiment, the herbicide was applied to vegetating sunflower plants in a dose causing a 40-50\% crop damage. In 1 or 3 days a treatment was implemented with the antidote at a dose of $40 \mathrm{~g} / \mathrm{ha}$. Two substances that showed significant antidotal activity were identified. Their influence resulted in extra yields of sunflower that equaled 5,3-5.5 and 6.4-6.6 c/ha, respectively, which means 35-39 and 44-46\% antidote effect. Thus, the found compounds can be used as active ingredients to develop herbicide antidotes.

Keywords: herbicides, yield losses, sunflower, antidotes, screening, triazolopyrimidines, antidote effect

Современные технологии выращивания сельскохозяйственных культур предусматривают использование химических средств борьбы с сорной растительностью. Гербициды по масштабу использования лидируют в числе пестицидов в целом. В то же время они токсичны не только для сорняков, но наносят вред и культурным растени- ям [1]. При тщательном соблюдении регламентов химических обработок негативные последствия их применения минимальны. Но в практике растениеводства нередки случаи повреждения значительных площадей сельскохозяйственных культур гербицидами вследствие сноса при наземных и особенно авиаобработках, воздействия па- 
ров летучих соединений, непреднамеренного внесения с поливной водой, и в случае некачественной промывки опрыскивающей аппаратуры [2]. Возможны также повреждения культур в результате передозировки препарата. Поэтому в арсенале средств защиты культурных растений должны быть средства снижения фитотоксического действия гербицидов - антидоты, необходимым требованием к которым является сохранение уровня гербицидной активности в отношении сорняков [3]. Исследования по поиску новых антидотов интенсивно проводятся в нашей стране и за рубежом. Гербицидные антидоты в настоящее время вызывают все больший интерес для практического использования в системах интегрированной защиты растений, все большее значение приобретает химическое адаптирование основных сельскохозяйственных культур к гербицидам [4].

Подсолнечник - основная масличная культура в нашей стране, он занимает три четверти площади посевов всех масличных культур. Современные сорта подсолнечника содержат до 50\% масла. Высокая физиологическая активность, калорийность, вкусовые качества подсолнечного масла определяют большие объёмы его потребления. Краснодарский край является безусловным лидером по производству семян подсолнечника, здесь сосредоточено около $40 \%$ площадей этой культуры (625 тыс. га) [5]. В то же время подсолнечник является очень чувствительной культурой к гербицидам группы 2,4-Д, и при непреднамеренном воздействии последних потери урожая могут быть невосполнимыми.

В связи с этим весьма актуальным является поиск путей и способов как повышения урожайности подсолнечника и выхода масла, так и спасения урожая в случае такой необходимости. Одним их таких приёмов является создание и использование антидотов, нивелирующих негативное действие гербицидов на растения и окружающую среду.

Целью настоящей работы являлся поиск антидотов 2,4-Д для вегетирующих растений подсолнечника от повреждающего действия фитотоксикантов группы 2,4-Д. Поиск осуществляли в ряду производных триазолопиримидинов. Ранее нами были выявлены эффективные антидоты в нескольких классах гетероциклических соединений - пиразолопиридинов, тиенопиридинов, пиридилгидразонов и др. [6, 7].

Для скрининга антидотов нами синтезирована серия $\mathrm{N}$-замещённых 4,6-диметил-
$1,2,4$ - триазоло $[1,5-b]$ пиримидил - 3 сульфониламидов общей формулы I:<smiles>[R]N([R])S(=O)(=O)c1nc2nc(C)cc(C)n2n1</smiles>

где Ia $\mathrm{R}=\mathrm{H}, \mathrm{R}^{1}=3$-хлор-4-фторфенил; $\mathrm{R}^{3}=\mathrm{H} ; \quad$ Ib $\mathrm{R}=\mathrm{H}, \quad \mathrm{R}^{1}=3,4,5$-триметоксифенил; Ic $\mathrm{R}=$ метил, $\mathrm{R}^{1}=4$-хлорфенил; Id $\mathrm{R}=\mathrm{H}, \mathrm{R}^{1}=2,4$-диметоксифенил; Ie $\mathrm{R}=\mathrm{H}$, $\mathrm{R}^{1}=2,5$-диэтоксифенил; If $\mathrm{R}=\mathrm{H}, \mathrm{R}^{1}=4$-метоксифенил; Ig R = H, R 1 = 2-метилпентил; Ih $\mathrm{R}=\mathrm{H}, \mathrm{R}^{1}=$ циклогептил $\mathbf{I i} \mathrm{R}=$ метил, $\mathrm{R}^{1}=$ циклогексил; Ij R = H, R ${ }^{1}=2$-метокси5-хлорфенил.

Для синтеза использовали известные и оригинальные методики, разработанные нами ранее [8]. Структуры синтезированных соединений подтверждены элементным анализом, методами ИК- и ЯМР $1 \mathrm{H}$ спектроскопии и масс-спектрометрии, определены их физико-химические константы.

Изучение антидотных свойств синтезированных соединений проводили в два этапа: в условиях лабораторного опыта отбирали вещества, проявляющие защитный эффект, затем исследовали их активность в полевом опыте.

\section{Материалы и методы исследования}

В наших исследованиях мы использовали методику лабораторного опыта определения антидотного эффекта новых соединений, разработанную ранее во ВНИИ биологической защиты растений. Опыты проводились на семенах подсолнечника сорта Родник.

Предварительно пророщенные семена подсолнечника с длиной корешка 2-4 мм выдерживали 1 ч в растворе 2,4-дихлорфеноксиуксусной кислоты $(2,4-Д)$ концентрации $1 \cdot 10^{-3} \%$ с целью получения 40-60\% ингибирования роста. Затем проростки промывали водой и помещали на 1 ч в растворы исследуемых веществ. Растворы последних готовили методом разбавления, их концентрации составляли $1 \cdot 10^{-2}, 1 \cdot 10^{-3}, 1 \cdot 10^{-4}$, $1 \cdot 10^{-5} \%$ (вариант гербицид+антидот).

В контрольном варианте проростки подсолнечника выдерживали 2 ч в воде; для эталона сравнения (гербицид) проростки выдерживали 1 ч в растворе 2,4-Д в концентрации $10^{-3} \%$ и 1 ч в воде. Через 1 ч обработанные семена промывали водой и раскладывали на полосы фильтровальной бумаги (размер 10х75 см) по 20 штук. Бумагу сворачивали в рулоны и помещали в стаканы с водой (50 мл воды). 
В термостате при температуре $28^{\circ} \mathrm{C}$ семена в стаканах с рулонами проращивались 3 суток, после чего измеряли длину стеблей и корней проростков. Антидотный эффект изучаемых веществ определяли по увеличению длины стебля и корня в варианте гербицид + антидот относительно названных величин в варианте гербицид (эталон) и рассчитывали по формуле

$$
\mathrm{A}_{\ni}=\frac{\mathrm{A}}{\ni} \times 100,
$$

где Аэ - антидотный эффект, \%;

А - длина стебля, корня в варианте гербицид + антидот, мм;

Э - длина стебля, корня в варианте гербицид (эталон), мм.

Полевые опыты проводились на экспериментальной базе ВНИИ биологической защиты растений, г. Краснодар, в период 2015-2017 гг. на растениях подсолнечника сорта Родник (по паспорту средняя урожайность 32 цга, максимальный урожай в производстве - 38,4 ц/га). В условиях поля вегетирующие растения подсолнечника в наиболее чувствительную фазу (1016 листьев) обрабатывали бутиловым эфиром 2,4-дихлорфеноксиуксусной кислоты $(2,4-Б . Э$.$) в дозе 14$ г/га с целью получения $40-60 \%$ снижения его урожайности и через 1 сутки или 3 суток наносили испытуемые вещества в дозе 40 г/га. Гербицид и антидот наносили на посевы подсолнечника полидисперсным пневматическим опрыскивателем с расходом рабочей жидкости 500 л/га.

Для растворения и эмульгирования препарата использовали спирт и эмульгатор ОП-7 с последующим разбавлением водой (концентрация ОП-7 и спирта в рабочем растворе составляла 0,05 и $0,2 \%$ соответственно). Опыты проводили на делянках площадью 2,8 м² (12 растений) при 4-кратной повторности. Расположение делянок последовательное многоярусное.

В схеме опыта предусматривались следующие варианты:

- гербицид + антидот - растения, обработанные гербицидом и через сутки антидотом;<smiles>Cc1cc(C)n2nc(S(=O)(=O)N(C)c3ccc(Cl)cc3)nc2n1</smiles>

- гербицид (эталон) - растения, обработанные гербицидом;

- контроль - необработанные растения.

Уборку урожая осуществляли со всей площади делянки в момент полного созревания семян методом прямого комбайнирования с помощью малогабаритного комбайна (Хеге-125).

Показателем степени защиты растений подсолнечника от повреждающего действия гербицида являлась прибавка урожая семян подсолнечника, полученная под действием антидота, относительно урожая обработанных гербицидом растений (вариант «гербицид» - эталон) и выражалась в процентах или ц/га.

Антидотную активность рассчитывали по формуле

$$
\mathrm{A}_{\ni}=\frac{\mathrm{A}}{\ni} \times 100
$$

где Аэ - антидотный эффект, \%;

A - урожай зерна подсолнечника в варианте гербицид + антидот, ц/га;

Э - урожай зерна подсолнечника в варианте гербицид (эталон), ц/га.

Достоверность различий между вариантами гербицид + антидот и эталоном (гербицид) при оценке антидотной активности осуществляли с помощью t-критерия Стьюдента при уровне вероятности $\mathrm{P}=0,90$.

\section{Результаты исследования и их обсуждение}

В числе синтезированных соединений в лабораторном опыте выявлены вещества, ослабляющие ингибирующее действие 2,4-Д на стебли проростков на 20-41\% при использовании в двух и более концентрациях. К таким соединениям относятся вещества Ic и Ie (табл. 1). Эти же соединения оказывали защитное действие на корни проростков на уровне $28-61 \%$ в двух и более концентрациях (табл. 1).

Таким образом, по результатам первичного скрининга нами отобраны потенциально активные соединения для изучения их антидотных свойств на вегетирующих растениях подсолнечника в условиях полевого опыта:<smiles>CCOc1ccc(OCC)c(NS(=O)(=O)c2nc3nc(C)cc(C)n3n2)c1</smiles> 
Таблица 1

Результаты испытаний производных триазолопиримидинов на антидотную активность к 2,4-Д на проростках подсолнечника (оценка по длине стебля и длине корня)

\begin{tabular}{|c|c|c|c|c|c|}
\hline \multirow{2}{*}{ Вариант } & \multirow{2}{*}{ Концентрация, \% } & \multicolumn{2}{|c|}{ Длина стебля } & \multicolumn{2}{|c|}{ Длина корня } \\
\cline { 3 - 6 } & & мм & $\%$ & мм & $\%$ \\
\hline Контроль (необработ.) & - & 71 & - & 169 & 100 \\
\hline Гербицид (эталон) & $10^{-3}$ & 45 & 37 & 63 & 73 \\
\hline \multirow{2}{*}{ соед. Iс } & $10^{-2}$ & 59 & $131^{*}$ & 93 & $147^{*}$ \\
\cline { 2 - 6 } & $10^{-3}$ & 61 & $136^{*}$ & 91 & $145^{*}$ \\
\cline { 2 - 6 } & $10^{-4}$ & 63 & $140^{*}$ & 81 & $128^{*}$ \\
\cline { 2 - 6 } & $10^{-5}$ & 54 & $120^{*}$ & 87 & $138^{*}$ \\
\cline { 2 - 6 } & $10^{-2}$ & 53 & $119^{*}$ & 88 & $139^{*}$ \\
\cline { 2 - 6 } & $10^{-3}$ & 64 & $141^{*}$ & 97 & $154^{*}$ \\
\cline { 2 - 6 } & $10^{-4}$ & 60 & $134^{*}$ & 100 & $161^{*}$ \\
\hline \multirow{2}{*}{ соед. Ie } & $10^{-5}$ & 60 & $133^{*}$ & 73 & $118^{*}$ \\
\hline
\end{tabular}

Пр и меч а н и е. * различия достоверны при $\mathrm{P}=0,90$.

Таблица 2

Антидотная активность триазолопиримидинов к 2,4-Д на растениях подсолнечника сорта Родник в полевых испытаниях (2015-2017 гг.)

\begin{tabular}{|c|c|c|c|c|c|c|}
\hline \multirow{4}{*}{$\begin{array}{c}\text { Шифр } \\
\text { соединения }\end{array}$} & \multirow{4}{*}{$\begin{array}{c}\text { Доза } \\
\text { антидота, } \\
\text { г/га }\end{array}$} & \multicolumn{5}{|c|}{ Варианты опыта } \\
\hline & & \multirow{3}{*}{$\begin{array}{c}\text { контроль } \\
\text { урожайность, } \\
\text { ц/га }\end{array}$} & \multirow{3}{*}{$\begin{array}{c}\text { 2,4-Д (эталон) } \\
\text { урожайность, } \\
\text { ц/га }\end{array}$} & \multicolumn{3}{|c|}{ 2,4-Д + антидот } \\
\hline & & & & \multirow[t]{2}{*}{$\begin{array}{c}\text { урожайность, } \\
\text { ц/га }\end{array}$} & \multicolumn{2}{|c|}{$\begin{array}{c}\text { антидотная активность, } \\
\text { прибавка к эталону }\end{array}$} \\
\hline & & & & & ц/га & $\%$ \\
\hline \multicolumn{7}{|c|}{2015 г. } \\
\hline Ic & 80 & 31,2 & 13,8 & 17,7 & 3,9 & 28 \\
\hline Ie & 80 & 31,2 & 13,8 & 18,4 & 4,6 & 33 \\
\hline $\mathrm{HCP}_{0,5}$ & & 2,04 & 1,41 & 1,68 & 0,13 & - \\
\hline \multicolumn{7}{|c|}{2016 г. } \\
\hline Ic & 80 & 32,1 & 15,2 & 19,6 & 4,4 & 29 \\
\hline Ic & 40 & 32,1 & 15,2 & 20,5 & 5,3 & 35 \\
\hline Ie & 80 & 32,1 & 15,2 & 20,8 & 5,6 & 37 \\
\hline $\mathrm{Ie}$ & 40 & 32,1 & 15,3 & 21,9 & 6,6 & 44 \\
\hline $\mathrm{HCP}_{0,5}$ & & 2,26 & 1,54 & 1,77 & 1,09 & - \\
\hline \multicolumn{7}{|c|}{2017 г. } \\
\hline \multicolumn{7}{|c|}{ через сутки после нанесения гербицида } \\
\hline Ic & 40 & 33,9 & 14,0 & 19,5 & 5,5 & 39 \\
\hline Ie & 40 & 33,9 & 14,0 & 20,4 & 6,4 & 46 \\
\hline \multicolumn{7}{|c|}{ через 3 суток после нанесения гербицида } \\
\hline Ic & 40 & 33,9 & 14,0 & 19,2 & 5,2 & 37 \\
\hline Ie & 40 & 33,9 & 14,0 & 20,3 & 6,3 & 45 \\
\hline $\mathrm{HCP}_{0,5}$ & & 2,15 & 1,38 & 1,46 & 1,21 & - \\
\hline
\end{tabular}

В табл. 2 представлены данные полевых испытаний соединений Ic и Ie за период 2015-2017 гг. В условиях поля оба препарата обеспечили значительное снижение фитотоксичности 2,4-Д, причем более эффективной оказалась доза 40 г/га.

Под влиянием антидотов прибавка урожая в случае применения Ic в оптималь- ной дозе составила 5,3-5,5 ц/га (35-39\%), в случае применения Ie - 6,4-6,6 ц/га (44$46 \%$ при нанесении через сутки после обработки гербицидом. В вариантах 2017 г., предусматривающих применение антидота через 3 суток после повреждения гербицидом, эффективность исследуемых веществ оставалась практически на том же уровне. 


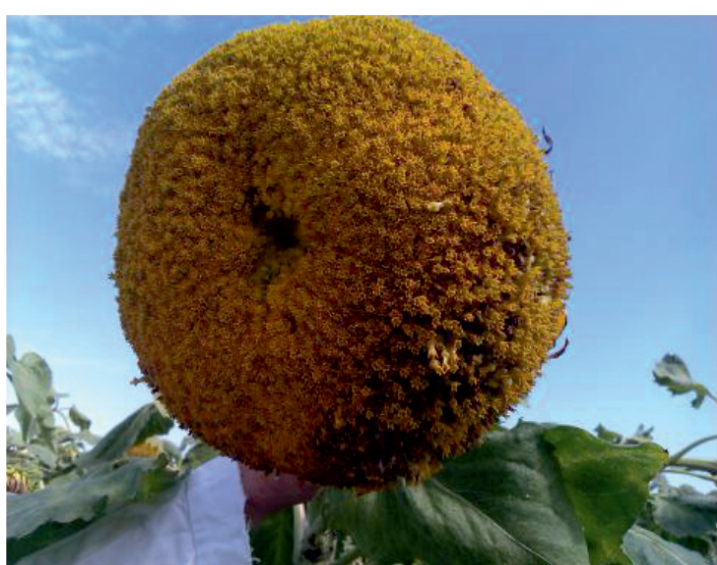

Рис. 1. Подсолнечник в варианте эталон (обработан только гербицидом)

Увеличение урожайности подсолнечника вследствие применения антидотов связано с их положительным влиянием на морфологию растений. Под их воздействием увеличилась высота растений, площадь листьев, уменьшилась деформация листьев и корзинки, увеличилось количество оформленных семян в корзинке и их масса. На рис. 1 представлено фото подсолнечника, корзинка которого деформирована воздействием гербицида, семена слабо оформлены, урожайность низкая. На рис. 2 - подсолнечник после воздействия гербицида и антидота: корзинка имеет правильную форму, количество семян больше, чем в гербицидном эталоне, масса 1000 семян возросла более чем на $40 \%$. Величина сохраненного урожая в результате применения антидота составила 39-46\%.

Наряду с антидотными мы исследовали и рострегулирующие свойства соединений 1c и 1е. Для их определения использовали стандартную методику [9]. В качестве контроля использовали необработанные растения. Размер, расположение делянок, сроки, способ и доза нанесения веществ 1с и 1e аналогичны таковым в опытах по изучению антидотного эффекта. Следует отметить, что соединения, обнаружившие антидотную активность, не обладают рострегулирующим действием, следовательно, снижение фитотоксичности гербицида не могло быть его проявлением.

\section{Заключение}

Риск поражения сельскохозяйственных культур при использовании пестицидов привел к развитию нового направления - созда-

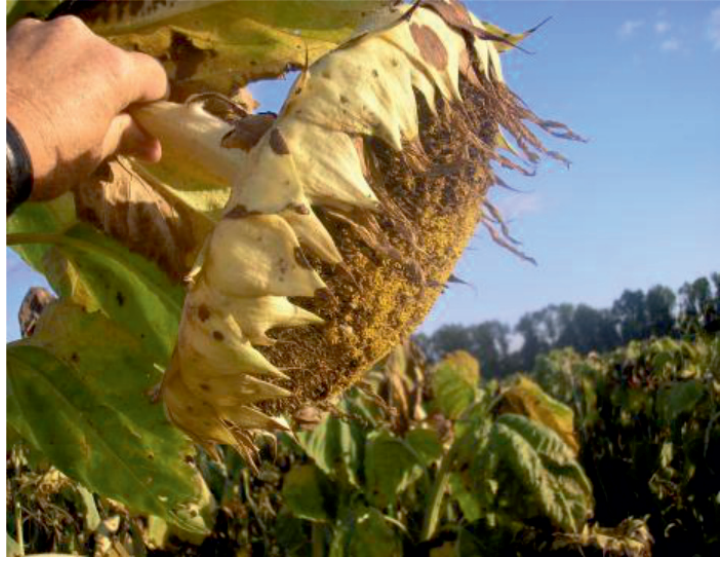

Рис. 2. Подсолнечник в варианте гербииид + антидот

нию средств защиты растений, способных уменышить отрицательное воздействие в результате реализации различных механизмов, часто за счёт повышения иммунитета самого растения. При этом наибольшую опасность для объектов растениеводства представляют, как ни парадоксально, химические средства борьбы с сорной растительностью, которые могут либо уничтожить посевы, либо сделать продукцию непригодной для питания человека и животных [10]. Таким образом, защита культурных растений от негативного действия гербицидов приобретает особую актуальность; при этом, если защита от почвенных гербицидов достаточно надежно обеспечена набором коммерческих антидотов, то защита вегетирующих растений при поражении их гербицидами является весьма сложной и вопрос этот совершенно не решен.

Найденные нами новые действующие вещества могут послужить основой создания отечественных антидотов, способных уменьшить фитотоксическое действие гербицидов группы 2,4 Д на растения подсолнечника, увеличить сопротивляемость культуры и тем самым сохранить урожай в случае чрезвычайной ситуации.

Работа выполнена при поддержке гранта РФФИ № 16-44-230215 p_a и администрации Краснодарского края.

\section{Список литературы}

1. Спиридонов Ю.Я. Современное состояние проблемы изучения и применения гербицидов (Обзор публикаций за 2011-2013 гг.) / Ю.Я. Спиридонов, С.Г. Жемчужин // Агрохимия. - 2016. - № 5. - С. 76-85.

2. Современный уровень и перспективные направления защиты сельскохозяйственных культур от нежелательных последствий применения гербицидов / М.Р. Питина [и др.] // Агрохимия. - 1985. - № 4. - С. 107-136. 
3. Угрюмов Е.П. Гербициды и культурные растения / Е.П. Угрюмов // Проблемы защиты растений на Северном Кавказе. Краснодар. - 1991. - С. 16-20.

4. Спиридонов Ю.Я. Антидоты гербицидов / Ю.Я. Спиридонов, П.С. Хохлов, В.Г. Шестаков // Агрохимия. - 2009. № 5. - С. 81-91.

5. Алиев-Лещенко Р.М. Влияние регуляторов роста растений на урожайность и качество подсолнечника при разных дозах минеральных удобрений: автореф. дис. ... канд. с.-х. наук / Р.М. Алиев-Лещенко. - Москва, 2015. - 26 с.

6. Антидотная активность производных пиразолопиридинов / В.Д. Стрелков [и др.] // Агрохимия. - 2010. - № 10. С. $28-31$.

7. Химические аспекты разработки новых регуляторов роста и гербицидных антидотов для сельскохозяйственных растений / И.Г. Дмитриева [и др.] // Труды Кубанского государственного аграрного университета - 2015. - № 53. C. $98-103$.

8. Синтез 4,6-диметил-5-R-3-цианопиридин-2сульфонилхлоридов и $\mathrm{N}$ - замещённых сульфониламидов на их основе / И.Г. Дмитриева [и др.] // Химия гетероциклических соединений. - 2009. - № 9. - С. 1311-1318.

9. Краткие методические указания по проведению государственных испытаний регуляторов роста растений. - М: ЦИНАО, 1984. - 20 с.

10. Надыкта В.Д. Агротерроризм - общие понятия и способы противодействия / В.Д. Надыкта // Наука и образование для целей безопасности: материалы пятой междунар. науч. конф. - Пущино, 2008. - С. 79-80.

\section{References}

1. Spiridonov Yu.Ya. Sovremennoe sostoyanie problemy izucheniya i primeneniya gerbicidov (Obzor publikacij za 2011-
2013 gg.) / Yu.Ya. Spiridonov, S.G. Zhemchuzhin // Agroximiya. - 2016. - № 5. - P. 76-85

2. Sovremenny`j uroven' i perspektivny`e napravleniya zashhity` sel'skoxozyajstvenny`x kul'tur ot nezhelatel'ny`x posledstvij primeneniya gerbicidov / M.R. Pitina [i dr.] // Agroximiya. - 1985. - № 4. - P. 107-136.

3. Ugryumov E.P. Gerbicidy`i kul'turny`e rasteniya/ E.P. Ugryumov // Problemy` zashhity` rastenij na Severnom Kavkaze. Krasnodar. - 1991. - P. 16-20.

4. Spiridonov Yu.Ya. Antidoty` gerbicidov/ Yu.Ya. Spiridonov, P.S. Xoxlov, V.G. Shestakov// Agroximiya. - 2009. № 5. - P. 81-91

5. Aliev-Leshhenko R.M. Vliyanie regulyatorov rosta rastenij na urozhajnost' i kachestvo podsolnechnika pri razny`x dozax mineral'ny`x udobrenij: avtoref. dis. ... kand. s.-x. nauk/ R.M. Aliev-Leshhenko. - Moskva, 2015. - 26 p.

6. Antidotnaya aktivnost' proizvodny'x pirazolopiridinov / V.D. Strelkov [i dr.] // Agroximiya. - 2010. - № 10. - P. 28-31.

7. Ximicheskie aspekty' razrabotki novy'x regulyatorov rosta $\mathrm{i}$ gerbicidny $\mathrm{x}$ antidotov dlya sel'skoxozyajstvenny'x rastenij / I.G. Dmitrieva [i dr.] // Trudy` Kubanskogo gosudarstvennogo agrarnogo universiteta - 2015. - № 53. - P. 98-103.

8. Sintez 4,6-dimetil-5-R-3-cianopiridin-2-sul' fonilxloridov i N- zameshhyonny`x sul'fonilamidov na ix osnove/ I.G. Dmitrieva [i dr.] // Ximiya geterociklicheskix soedinenij. - 2009. № 9. - P. 1311-1318.

9. Kratkie metodicheskie ukazaniya po provedeniyu gosudarstvenny`x ispy`tanij regulyatorov rosta rastenij. - M: CINAO, 1984. -20 p.

10. Nady`kta V.D. Agroterrorizm - obshhie ponyatiya i sposoby' protivodejstviya / V.D. Nady'kta // Nauka i obrazovanie dlya celej bezopasnosti: materialy` pyatoj mezhdunar. nauch. konf. - Pushhino, 2008. - P. 79-80. 